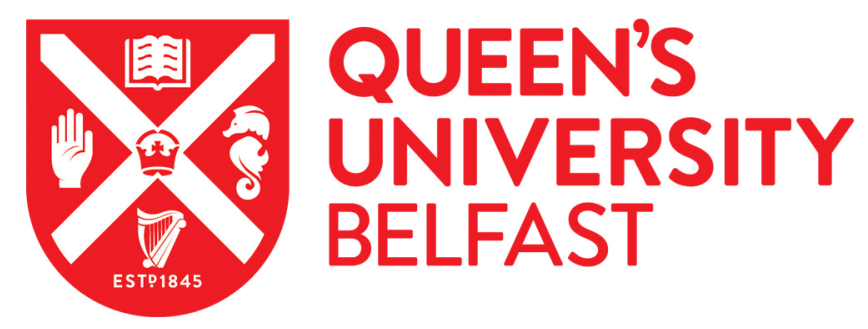

\title{
Interplay between Vacuum-Grown Monolayers of Alkylphosphonic Acids and the Performance of Organic Transistors Based on Dinaphtho[2,3-b 2',3'-f]thieno[3,2-b]thiophene
}

Hannah, S., Cardona, J., Lamprou, D. A., Šutta, P., Baran, P., Al Ruzaiqi, A., Johnston, K., \& Gleskova, H. (2016). Interplay between Vacuum-Grown Monolayers of Alkylphosphonic Acids and the Performance of Organic Transistors Based on Dinaphtho[2,3-b 2',3'-f]thieno[3,2-b]thiophene. ACS Applied Materials and Interfaces, 8(38), 25405-25414. https://doi.org/10.1021/acsami.6b08426

Published in:

ACS Applied Materials and Interfaces

Document Version:

Publisher's PDF, also known as Version of record

Queen's University Belfast - Research Portal:

Link to publication record in Queen's University Belfast Research Portal

\section{Publisher rights}

Copyright 2018 the authors.

This is an open access article published under a Creative Commons Attribution License (https://creativecommons.org/licenses/by/4.0/), which permits unrestricted use, distribution and reproduction in any medium, provided the author and source are cited.

\section{General rights}

Copyright for the publications made accessible via the Queen's University Belfast Research Portal is retained by the author(s) and / or other copyright owners and it is a condition of accessing these publications that users recognise and abide by the legal requirements associated with these rights.

Take down policy

The Research Portal is Queen's institutional repository that provides access to Queen's research output. Every effort has been made to ensure that content in the Research Portal does not infringe any person's rights, or applicable UK laws. If you discover content in the

Research Portal that you believe breaches copyright or violates any law, please contact openaccess@qub.ac.uk. 


\title{
Interplay between Vacuum-Grown Monolayers of Alkylphosphonic Acids and the Performance of Organic Transistors Based on Dinaphtho[2,3-b:2', $\left.3^{\prime}-f\right]$ thieno[3,2-b]thiophene
}

\author{
Stuart Hannah, ${ }^{\dagger}$ Javier Cardona, ${ }^{\ddagger}$ Dimitrios A. Lamprou, ${ }^{\S}$ Pavol Šutta, ${ }^{\|}$Peter Baran, ${ }^{\perp}$ Afra Al Ruzaiqi, ${ }^{\dagger}$
} Karen Johnston, ${ }^{*}$, and Helena Gleskova*, ${ }^{\dagger}$

${ }^{\dagger}$ Department of Electronic and Electrical Engineering, University of Strathclyde, 204 George Street, Glasgow G1 1XW, United
Kingdom

${ }^{\ddagger}$ Department of Chemical and Process Engineering, University of Strathclyde, James Weir Building, 75 Montrose Street, Glasgow G1 1XJ, United Kingdom

${ }^{\S}$ Strathclyde Institute of Pharmacy and Biomedical Sciences, University of Strathclyde, 161 Cathedral Street, Glasgow G4 0RE, United Kingdom

"New Technologies Research Centre, University of West Bohemia, Univerzitní 8, 30614 Pilsen, Czech Republic

${ }^{\perp}$ Department of Chemistry, Juniata College, 2035 von Liebig Science Center, Huntingdon, Pennsylvania 16652, United States

\section{Supporting Information}

ABSTRACT: Monolayers of six alkylphosphonic acids ranging from $C_{8}$ to $C_{18}$ were prepared by vacuum evaporation and incorporated into low-voltage organic

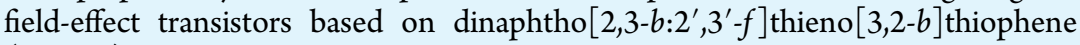
(DNTT). Similar to solution-assembled monolayers, the molecular order for vacuum-deposited monolayers improved with increasing length of the aliphatic tail. At the same time, Fourier transform infrared (FTIR) measurements suggested lower molecular coverage for longer phosphonic acids. The comparison of FTIR and vibration frequencies calculated by density functional theory indicated that monodentate bonding does not occur for any phosphonic acid. All monolayers exhibited low surface energy of $\sim 17.5 \mathrm{~mJ} / \mathrm{m}^{2}$ with a dominating

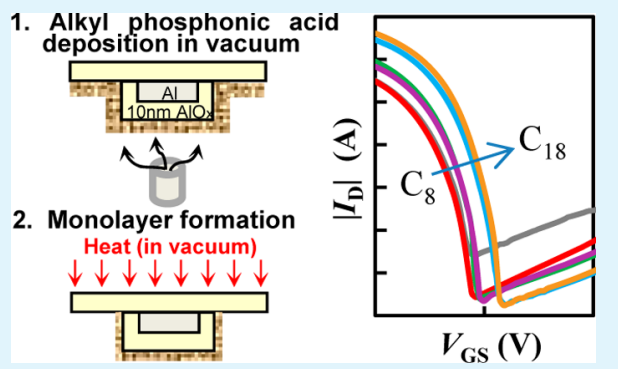
Lifshitz-van der Waals component. Their surface roughness was comparable, while the nanomechanical properties were varied but not correlated to the length of the molecule. However, large improvement in transistor performance was observed with increasing length of the aliphatic tail. Upon going from $\mathrm{C}_{8}$ to $\mathrm{C}_{18}$, the mean threshold voltage decreased from -1.37 to $-1.24 \mathrm{~V}$, the field-effect mobility increased from 0.03 to $0.33 \mathrm{~cm}^{2} /(\mathrm{V} \cdot \mathrm{s})$, the off-current decreased from $\sim 8 \times 10^{-13}$ to $\sim 3 \times 10^{-13} \mathrm{~A}$, and for transistors with $L=30 \mu \mathrm{m}$ the on-current increased from $\sim 3 \times 10^{-8}$ to $\sim 2 \times 10^{-6} \mathrm{~A}$, and the on/off-current ratio increased from $\sim 3 \times 10^{4}$ to $\sim 4 \times 10^{6}$. Similarly, transistors with longer phosphonic acids exhibited much better air and bias-stress stability. The achieved transistor performance opens up a completely "dry" fabrication route for ultrathin dielectrics and low-voltage organic transistors.

KEYWORDS: organic field-effect transistors, alkylphosphonic acids, monolayers, DNTT, bias stress

\section{INTRODUCTION}

The focused improvement of organic field-effect transistors (OFETs) has allowed a whole host of novel demonstrations including radio frequency identification tags, ${ }^{1,2}$ analog and digital circuits, ${ }^{3-5}$ active matrix displays, ${ }^{6}$ and various sensor systems. $^{7-9}$ However, when the application of OFETs in forthcoming areas such as wearable or disposable electronics is considered, low power consumption and low-voltage operation are necessary features, especially for applications powered by batteries or energy-harvesting devices.

A common approach to achieving low-voltage transistor operation is to increase the gate dielectric capacitance by choosing thin layers and/or materials with high relative permittivity (high- $k$ ). To date, approaches have included single layers of inorganic or organic high- $k$ materials, inorganic/ organic bilayers, and organic/inorganic composites. ${ }^{10,11}$ Reduction in the gate dielectric thickness to $10 \mathrm{~nm}$ or less typically involves a bilayer, where a medium- $k$ to high- $k$ inorganic layer is covered with an organic monolayer whose function is to suppress the leakage current, inhibit the surface $-\mathrm{OH}$ groups, and reduce the energy of the dielectric surface. ${ }^{12-17}$ In such a case, the transistor operating voltage can be as low as $1.5 \mathrm{~V}$, while the transistor is in the off state at $0 \mathrm{~V}^{18-20}$

As the thickness of the dielectric is reduced, small variations in its thickness lead to more pronounced variations in its capacitance. Consequently, procedures that inherently lend

Received: July 12, 2016

Accepted: September 1, 2016

Published: September 1, 2016 
themselves to good layer uniformity (atomic layer deposition) or self-limit the layer thickness (oxidation or use of monolayers) are advantageous. Aluminum oxide $\left(\mathrm{AlO}_{x}\right)$ functionalized with alkylphosphonic acids $\left(\mathrm{C}_{n} \mathrm{PA}\right)$ is an established bilayer dielectric for low-voltage organic transistors. ${ }^{12}$ Such transistors have a bottom-gate structure where the aluminum oxide is commonly prepared by oxidation of the aluminum gate electrode and the assembly of the organic monolayer is performed in solvent-based solutions. A dry route to monolayer assembly has also been demonstrated for $n$ octylphosphonic acids $\left(\mathrm{C}_{8} \mathrm{PA}\right) .^{21-23}$ In such a case, several monolayers of $\mathrm{C}_{8} \mathrm{PA}$ were thermally evaporated in vacuum, followed by thermal desorption of all molecules that were not chemically bonded to $\mathrm{AlO}_{x}$. In such a technique, nonuniformity in the as-deposited $\mathrm{C}_{8} \mathrm{PA}$ thickness is eliminated during the second step of thermal desorption, leaving monolayer formation across the substrate. Thermal desorption provides an additional benefit of annealing that improves both the monolayer structure and transistor performance. ${ }^{23}$

In this paper we report bottom-gate OFETs based on various $\mathrm{AlO}_{x} / \mathrm{C}_{n} \mathrm{PA}$ dielectrics and an air-stable ${ }^{24,25}$ organic semiconductor, dinaphtho $\left[2,3-b: 2^{\prime}, 3^{\prime}-f\right]$ thieno $[3,2-b]$ thiophene (DNTT). This was prompted by previous research on solution-assembled $\mathrm{C}_{n} \mathrm{PA}$ that observed better transistor performance if longer-chain $\mathrm{C}_{n} \mathrm{PA}$ were used. Contrary to solution assembly, this work uses a series of alkylphosphonic acids that were thermally evaporated in vacuum and incorporated into transistors. The dielectrics and the corresponding transistors were fully characterized, including the transistor bias-stress stability. The experiment was accompanied by density functional theory (DFT) calculations to provide insight into the structure of $\mathrm{C}_{n} \mathrm{PA}$ monolayers and the corresponding transistor behavior. The achieved transistor performance opens up a completely "dry" fabrication route for ultrathin dielectrics.

\section{EXPERIMENTAL SECTION}

All samples/devices were fabricated on precleaned Eagle 2000 glass (Scientific Glass). 99.999\% aluminum and 99.99\% gold were used. Six alkylphosphonic acids with varying length of the aliphatic tail $\left(\mathrm{C}_{8} \mathrm{PA}\right.$, $\mathrm{C}_{10} \mathrm{PA}, \mathrm{C}_{12} \mathrm{PA}, \mathrm{C}_{14} \mathrm{PA}, \mathrm{C}_{16} \mathrm{PA}, \mathrm{C}_{18} \mathrm{PA}$ ) were purchased with $97 \%$ purity (Strem Chemicals) and purified by recrystallization from hot hexane or heptane solutions with decolorizing charcoal. Dinaphtho[2,3$\left.\mathrm{b}: 2^{\prime}, 3^{\prime}-f\right]$ thieno[3,2-b] thiophene (DNTT) purified by sublimation was purchased from Sigma-Aldrich.

$\mathrm{AlO}_{x}$ and $\mathrm{AlO}_{x} / \mathrm{C}_{n} \mathrm{PA}$ samples for structural and surface characterization were prepared as follows. A $30 \mathrm{~nm}$ thick aluminum layer was evaporated on Eagle 2000 glass at a rate of $\sim 2.5 \AA / \mathrm{s}$. Next, approximately $10 \mathrm{~nm}$ thick $\mathrm{AlO}_{x}$ was prepared by exposing the aluminum to UV/ozone cleaning system (UVOCS) in ambient atmosphere. ${ }^{21}$ To prevent contamination of the oxidizing surface, the UV/ozone cleaner was enclosed under a high-efficiency particulate air (HEPA) filter. All $\mathrm{C}_{n} \mathrm{PA}$ layers were grown in high vacuum in a MiniSpectros (K. J. Lesker) evaporation chamber enclosed in a $\mathrm{N}_{2}$-filled glovebox (Jacomex). On the basis of previously optimized $\mathrm{C}_{8} \mathrm{PA}$ growth, ${ }^{21-23}$ the evaporation rate of each $\mathrm{C}_{n} \mathrm{PA}$ was adjusted to achieve a "monolayer thickness" in about $5.5 \mathrm{~s}$, while the as-deposited thickness was equal to $\sim 9$ monolayers. The substrate was kept at room temperature during the evaporation of each $\mathrm{C}_{n} \mathrm{PA}$. Afterward, the substrate temperature was raised to $\sim 160{ }^{\circ} \mathrm{C}$ for $3 \mathrm{~h}$ to remove all physisorbed molecules. Fourier transform infrared (FTIR) spectroscopy, atomic force microscopy (AFM), and contact angle goniometry (CAG) measurements were performed on such surfaces. In addition, measurements of the $\mathrm{AlO}_{x}$ reference surface (as prepared and annealed for $3 \mathrm{~h}$ at $\sim 160{ }^{\circ} \mathrm{C}$ ) were performed for comparison.
FTIR spectra were measured in reflection mode on a Nicolet 380 spectrometer (Thermo Scientific) equipped with attenuated total reflectance (ATR) accessory with Ge crystal. The beam diameter was $\sim 1.5 \mathrm{~mm}$. The spectral line profile analysis was evaluated by PeakFit software, analyzing the peak positions, full widths at half-maximum (fwhm), integrated intensities (areas below the line profile), and peak heights.

AFM images were obtained by scanning $1 \times 1 \mu \mathrm{m}^{2}$ areas of surface in ambient air by use of a MultiMode 8 scanning probe microscope (Digital Instruments; Bruker Nanoscope analysis software version 1.40) under the new PeakForce quantitative nanomechanical mapping (QNM) mode. The AFM measurements were obtained by use of ScanAsyst air probes. The spring constant $(0.47 \mathrm{~N} / \mathrm{m}$; nominal $0.4 \mathrm{~N} /$ $\mathrm{m})$ and deflection sensitivity have been calibrated, while the nominal value for the tip radius $(2 \mathrm{~nm})$ was used. Surface roughness values were determined after employing a digital leveling algorithm (Bruker Image Analysis Nanoscope analysis software v1.5). AFM images were collected at random spots in at least two areas. PeakForce QNM also enables direct extraction of the nanomechanical properties of the samples without damaging them. Each time the tip contacts the sample, the captured force curve is used to calculate the DMT modulus, deformation, energy dissipation, and force of adhesion. To obtain the Young's modulus, the retract curve is fitted by use of the Derjaguin-Muller-Toporov (DMT) model, for that reason called DMT modulus.

To probe liquid-surface interactions with maximum resolution, contact angles (at $22{ }^{\circ} \mathrm{C}$ ) of small drops (four on each substrate) of diiodomethane (DIM, $>99 \%$, surface tension $\gamma_{1}=48.7 \mathrm{mN} / \mathrm{m}$ at 18.8 ${ }^{\circ} \mathrm{C}$, $\sim 1 \mu \mathrm{L}$ ), 1,2-ethanediol or ethylene glycol (EG, $>99 \%, \gamma_{1}=47.7$ $\mathrm{mN} / \mathrm{m}$ at $\left.18.8^{\circ} \mathrm{C}, \sim 1 \mu \mathrm{L}\right)$, and filtered water $\left(\mathrm{FW}, \gamma_{1}=73.4 \mathrm{mN} / \mathrm{m}\right.$ at $18.8{ }^{\circ} \mathrm{C}, \sim 2 \mu \mathrm{L}$ ) placed on horizontal surfaces were measured by use of a contact angle goniometer (Kruss DSA30, Germany). Advancing angles $\left(\theta_{\mathrm{A}}\right)$ were obtained for both "left" and "right" contact angles about $20-30 \mathrm{~s}$ after placement of the drop. ${ }^{26}$ Surface energies $\left(\gamma_{\mathrm{s}}\right)$ of the probed solid surfaces were calculated from contact angles and interfacial energies $\left(\gamma_{1}\right)$ of the three probe liquids by use of eqs $1-3^{27}$ and an in-house Visual Basic program. Total surface energy is the sum of Lifshitz-van der Waals (also called dispersion or nonpolar) and acid-base (also called polar) contributions. The polar portion can be further subdivided into Lewis acid and Lewis base components.

$$
\begin{aligned}
& \gamma_{\mathrm{s}}=\gamma_{\mathrm{s}}^{\mathrm{LW}}+\gamma_{\mathrm{s}}^{\mathrm{AB}}=\gamma_{\mathrm{s}}^{\mathrm{LW}}+2\left(\gamma_{\mathrm{s}}^{+} \gamma_{\mathrm{s}}^{-}\right)^{0.5} \\
& \gamma_{1}=\gamma_{1}^{\mathrm{LW}}+\gamma_{1}^{\mathrm{AB}}=\gamma_{1}^{\mathrm{LW}}+2\left(\gamma_{1}^{+} \gamma_{1}^{-}\right)^{0.5} \\
& \gamma_{1}(1+\cos \theta)=2\left[\left(\gamma_{\mathrm{s}}^{\mathrm{LW}} \gamma_{1}^{\mathrm{LW}}\right)^{0.5}+\left(\gamma_{\mathrm{s}}^{+} \gamma_{1}^{-}\right)^{0.5}+\left(\gamma_{\mathrm{s}}^{-} \gamma_{1}^{+}\right)^{0.5}\right]
\end{aligned}
$$

In eqs $1-3$, superscripts denote components of the surface energy: LW, Lifshitz-van der Waals; $\mathrm{AB}$, acid-base; $\gamma^{+}$, Lewis acid; and $\gamma^{-}$, Lewis base. In FW, $\gamma_{1}^{\mathrm{LW}}=21.8 \mathrm{~mJ} / \mathrm{m}^{2}$ and $\gamma_{1}^{+}=\gamma_{1}^{-}=25.5 \mathrm{~mJ} / \mathrm{m}^{2}$; in DIM, $\gamma_{1}^{\mathrm{LW}}=50.8 \mathrm{~mJ} / \mathrm{m}^{2}$ and $\gamma_{1}^{+}=\gamma_{1}^{-}=0 \mathrm{~mJ} / \mathrm{m}^{2}$; and in EG, $\gamma_{1}^{\mathrm{LW}}=29$ $\mathrm{mJ} / \mathrm{m}^{2}, \gamma_{1}^{+}=1.92 \mathrm{~mJ} / \mathrm{m}^{2}$, and $\gamma_{1}^{-}=47 \mathrm{~mJ} / \mathrm{m}^{2}{ }^{28}$

Six samples featuring both bottom-gate organic field-effect transistors (OFETs) and metal-insulator-metal (MIM) structures were fabricated side-by-side with the exception of thermal evaporation and desorption of alkylphosphonic acid $\left(\mathrm{C}_{n} \mathrm{PA}\right)$. One $\mathrm{C}_{n} \mathrm{PA}$ was used in each sample.

MIM and OFET structures followed the same fabrication procedure up to and including the phosphonic acid monolayer. All thermal evaporations (metals and organics) were performed in Mini-Spectros. First, $30 \mathrm{~nm}$ thick aluminum was evaporated on a glass substrate through a shadow mask. Part of each electrode was coated with $40 \mathrm{~nm}$ thick Au to prevent its oxidation. Next, all samples were exposed to $\mathrm{UV} /$ ozone to produce about $10 \mathrm{~nm}$ thick $\mathrm{AlO}_{x}$. $\mathrm{AlO}_{x}$ was functionalized with $\mathrm{C}_{n} \mathrm{PA}$ by the process described earlier. Some $\mathrm{AlO}_{x}$ was left uncoated to provide reference $\mathrm{AlO}_{x}$ MIM structures. Next, a $20 \mathrm{~nm}$ thick DNTT layer was thermally evaporated at a rate of $0.5 \AA / s$ at room temperature through a shadow mask. All MIM structures were masked during this step. Finally, a $50 \mathrm{~nm}$ thick Au layer was evaporated through a shadow mask at a rate of $\sim 3 \AA$ /s to 
complete the transistors and MIM structures. The transistors have nominal channel lengths of $30,50,70$, and $90 \mu \mathrm{m}$ and a channel width of $1000 \mu \mathrm{m}$.

Transistor and MIM measurements were performed with an Agilent B1500A semiconductor device analyzer under dark ambient conditions. All fabricated devices were kept in oxygen- and moisture-free environment until their measurement, and they shared the same history. The gate dielectric capacitance of MIM structures was measured between $1 \mathrm{kHz}$ and $1 \mathrm{MHz}$ and extracted at $100 \mathrm{kHz}$. The MIM current density was measured as a function of applied voltage between -3 and $3 \mathrm{~V}$. The transfer and output characteristics of the OFETs were measured in a sweep mode. The threshold voltage and field-effect mobility were extracted from the transfer characteristics measured in saturation by use of metal-oxide-semiconductor fieldeffect transistor (MOSFET) equations. Subthreshold slope, oncurrent, off-current, and on/off-current ratio were also extracted from the saturation curve. Mean values and standard deviations were calculated for all relevant transistor parameters. Bias stress was performed at $V_{\mathrm{GS}}=-2 \mathrm{~V}$ for $1000 \mathrm{~s}$ with source and drain electrodes grounded. At certain intervals, the bias stress was briefly interrupted and transistor transfer characteristics in saturation were measured to allow transistor parameter extraction.

Calculations were performed with density functional theory (DFT) as implemented in the Quantum Espresso (QE) package, version 5.1. ${ }^{29}$ The core electrons were represented by use of projectoraugmented wave potentials, ${ }^{30}$ and valence electrons were represented with a planewave basis with cutoffs of 50 and 400 Ry for the wave functions and charge densities, respectively. The PBE version ${ }^{31}$ of the generalized gradient approximation was used for the exchange and correlation functional. Self-consistent calculations used an electronic convergence threshold of $1 \times 10^{-8} \mathrm{Ry}$. Isolated molecules were generated with the aid of the chemical drawing tool Avogadro 1.1.1. ${ }^{32}$ The $\alpha$-alumina (0001) slabs were six $\mathrm{AlO}_{3} \mathrm{Al}$ layers thick, with a hexagonal lattice parameter of $4.80 \AA$. The top surface was terminated with an extra $\mathrm{Al}(\mathrm{OH})_{3}$ layer. Alkylphosphonic acid molecules with alkyl chain length from 2 to 18 carbon atoms were added on top of the relaxed $\mathrm{Al}_{2} \mathrm{O}_{3}$ (0001) hydroxylated surface with either monodentate or bidentate binding, by removing $\mathrm{H}$ atoms from the surface. The molecule, top $\mathrm{AlO}_{3} \mathrm{Al}$ layer, and hydroxylated $\mathrm{Al}(\mathrm{OH})_{3}$ layer were allowed to relax until a force convergence threshold of $1 \times 10^{-5}$ au was reached. A single $k$-point was used for the relaxation of isolated molecules, while a $3 \times 3 \times 1$ hexagonal $k$-point mesh was used when the surface was present. Periodic boundary conditions were implemented, and a vacuum layer of at least $7 \AA$ was added on top of the molecules, to avoid self-interaction.

Vibration frequencies were calculated by use of the Phonon package in $\mathrm{QE}$, and the self-consistency threshold was $1 \times 10^{-14} \mathrm{Ry}$. For a few cases (free acids, $\mathrm{C}_{14} \mathrm{PA}$ monodentate, and $\mathrm{C}_{18} \mathrm{PA}$ mono- and bidentate), the self-consistency threshold was $1 \times 10^{-18} \mathrm{Ry}$. The vibrational mode characters were assigned by visualizing individual vibrational modes with the Molden 5.3 package. ${ }^{33}$ It is important to note that for some frequencies it was difficult to identify independent vibrational modes due to the interference of a wide range of vibrational modes occurring at similar frequencies. The vibration spectra were created by a superposition of Gaussians. Each Gaussian is centered at an identified vibration frequency and has a standard deviation of 10 $\mathrm{cm}^{-1}$, and the area under the curve is proportional to the intensity of the mode.

\section{RESULTS AND DISCUSSION}

\subsection{Gate Dielectric: Electrical and Structural Measure-} ments. Figure la shows the capacitance of $\mathrm{AlO}_{x} / \mathrm{C}_{n} \mathrm{PA}$ bilayers and the thickness calculated for each alkylphosphonic acid. Total dielectric capacitance $\left(C_{\text {diel }}\right)$ consists of capacitance of the $\mathrm{AlO}_{x}$ layer $\left(C_{\mathrm{AlO}_{x}}\right)$ and capacitance of the phosphonic acid $\left(C_{\mathrm{C}_{n} \mathrm{PA}}\right)$. The two capacitances are in series, therefore $1 / C_{\text {diel }}=$ $1 / C_{\mathrm{AlO}_{x}}+1 / C_{\mathrm{C}_{n} \mathrm{PA}}$. This relationship can be rearranged to find
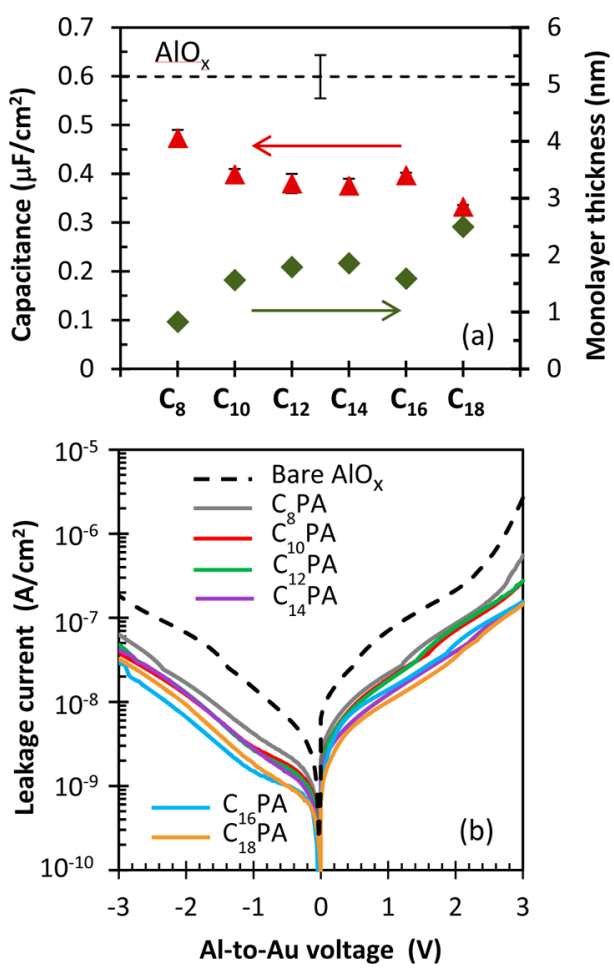

Figure 1. (a) $\mathrm{AlO}_{x} / \mathrm{C}_{n} \mathrm{PA}$ capacitance and extracted $\mathrm{C}_{n} \mathrm{PA}$ thickness versus $\mathrm{C}_{n} \mathrm{PA} . \mathrm{AlO}_{x}$ capacitance is given as a reference. (b) Current density of $\mathrm{AlO}_{x} / \mathrm{C}_{n} \mathrm{PA}$ bilayers as a function of $\mathrm{C}_{n} \mathrm{PA}$. Bare $\mathrm{AlO}_{x}$ is included for comparison.

$C_{\mathrm{C}_{n} \mathrm{PA}}$ which is then used to calculate $\mathrm{C}_{n} \mathrm{PA}$ thickness by using a relative permittivity value of 2.1. ${ }^{21}$ The capacitance of bare $\mathrm{AlO}_{x}$ has a mean value of $0.60 \mu \mathrm{F} / \mathrm{cm}^{2} . \mathrm{AlO}_{x} / \mathrm{C}_{n} \mathrm{PA}$ capacitance is lower, and a decrease in capacitance per unit area is seen as $\mathrm{C}_{n} \mathrm{PA}$ length increases. The increase in $\mathrm{C}_{n} \mathrm{PA}$ thickness from $0.83 \mathrm{~nm}$ for $\mathrm{C}_{8} \mathrm{PA}$ to $2.49 \mathrm{~nm}$ for $\mathrm{C}_{18} \mathrm{PA}$ is consistent with the increased linear length of $\mathrm{C}_{n} \mathrm{PA}$ molecules when $n$ increases from 8 to 18 .

$\mathrm{AlO}_{x}$ and $\mathrm{AlO}_{x} / \mathrm{C}_{n} \mathrm{PA}$ leakage current densities for various phosphonic acids are shown in Figure $1 \mathrm{~b}$. Bare $\mathrm{AlO}_{x}$ dielectric displays a leakage current density of $\sim 2 \times 10^{-7} \mathrm{~A} / \mathrm{cm}^{2}$ at $-3 \mathrm{~V}$. At the same voltage, $\mathrm{AlO}_{x}$ functionalized with phosphonic acid shows reduced leakage current density with values between $\sim 6$ $\times 10^{-8}$ and $\sim 3 \times 10^{-8} \mathrm{~A} / \mathrm{cm}^{2}$. Leakage current decreases as $\mathrm{C}_{n} \mathrm{PA}$ length increases. In summary, both capacitance and leakage current measurements confirmed that the thickness of $\mathrm{C}_{n} \mathrm{PA}$ increased with increasing $n$, while capacitance measurement determined that in all cases the $\mathrm{C}_{n} \mathrm{PA}$ thickness corresponds to about a monolayer.

Water contact angles of $\mathrm{AlO}_{x} / \mathrm{C}_{n} \mathrm{PA}$ as a function of $\mathrm{C}_{n} \mathrm{PA}$ length are shown in Table 1a. After annealing to remove physisorbed molecules, all $\mathrm{AlO}_{x} / \mathrm{C}_{n} \mathrm{PA}$ surfaces are hydrophobic, with water contact angles greater than $110^{\circ}$ regardless of the alkyl chain length. Although a maximum value of $112.0^{\circ}$ $\pm 1.1^{\circ}$ and a minimum value of $110.8^{\circ} \pm 1.3^{\circ}$ were obtained for $\mathrm{C}_{12} \mathrm{PA}$ and $\mathrm{C}_{14} \mathrm{PA}$ respectively, all contact angles are the same within the error of measurement. These contact angles were compared to a $\mathrm{C}_{18} \mathrm{PA}$ layer prior to annealing, whose thickness of $\sim 20 \mathrm{~nm}$ was confirmed by atomic force microscopy (AFM). This layer exhibits significantly different contact angles for all three liquids. 
Table 1. (a) Advancing Contact Angles of Probe Liquids on Various Surfaces and (b) Surface Energies Calculated from These Contact Angles

\begin{tabular}{|c|c|c|c|c|}
\hline \multirow[b]{2}{*}{ surface } & \multicolumn{4}{|c|}{ mean contact angle $\theta(\mathrm{deg})$} \\
\hline & \multicolumn{2}{|l|}{ FW } & EG & DIM \\
\hline $\mathrm{C}_{8} \mathrm{PA}$ & \multicolumn{2}{|l|}{$111.1 \pm 0.2$} & $70.4 \pm 2.3$ & $85.2 \pm 0.8$ \\
\hline $\mathrm{C}_{10} \mathrm{PA}$ & \multicolumn{2}{|l|}{$111.5 \pm 0.9$} & $71.4 \pm 1.3$ & $86.3 \pm 2.6$ \\
\hline $\mathrm{C}_{12} \mathrm{PA}$ & \multicolumn{2}{|l|}{$112.0 \pm 1.1$} & $70.9 \pm 5.2$ & $87.1 \pm 1.9$ \\
\hline $\mathrm{C}_{14} \mathrm{PA}$ & \multicolumn{2}{|l|}{$110.8 \pm 1.3$} & $71.2 \pm 4.9$ & $83.6 \pm 1.6$ \\
\hline $\mathrm{C}_{16} \mathrm{PA}$ & \multicolumn{2}{|l|}{$111.3 \pm 0.8$} & $68.7 \pm 1.7$ & $84.9 \pm 1.1$ \\
\hline $\mathrm{C}_{18} \mathrm{PA}$ & \multicolumn{2}{|l|}{$111.3 \pm 0.8$} & $70.8 \pm 3.2$ & $86.2 \pm 1.0$ \\
\hline $\mathrm{C}_{18} \mathrm{PA}^{c}$ & \multicolumn{2}{|l|}{$77.4 \pm 3.3$} & $82.5 \pm 0.4$ & $70.7 \pm 1.0$ \\
\hline \multicolumn{5}{|c|}{ (b) Surface Energies ${ }^{b}\left(\mathrm{~mJ} / \mathrm{m}^{2}\right)$} \\
\hline surface & $\gamma_{\mathrm{s}}^{+}$ & $\gamma_{\mathrm{s}}^{-}$ & $\gamma_{\mathrm{s}}^{\mathrm{LW}}$ & $\gamma_{\mathrm{s}}$ \\
\hline $\mathrm{C}_{8} \mathrm{PA}$ & 3.22 & 0.56 & 14.91 & $17.61 \pm 1.1$ \\
\hline $\mathrm{C}_{10} \mathrm{PA}$ & 3.18 & 0.53 & 14.39 & $16.98 \pm 1.2$ \\
\hline $\mathrm{C}_{12} \mathrm{PA}$ & 3.51 & 0.68 & 14.02 & $17.11 \pm 2.2$ \\
\hline $\mathrm{C}_{14} \mathrm{PA}$ & 2.73 & 0.44 & 15.69 & $17.89 \pm 2.1$ \\
\hline $\mathrm{C}_{16} \mathrm{PA}$ & 3.64 & 0.82 & 15.06 & $18.51 \pm 1.1$ \\
\hline $\mathrm{C}_{18} \mathrm{PA}$ & 3.30 & 0.55 & 14.44 & $17.13 \pm 1.2$ \\
\hline $\mathrm{C}_{18} \mathrm{PA}^{c}$ & 0.67 & 27.23 & 22.48 & $31.03 \pm 1.3$ \\
\hline
\end{tabular}

${ }^{a}$ FW, filtered water; EG, ethylene glycol; DIM, diiodomethane. ${ }^{b} \gamma_{s}^{\mathrm{LW}}$, Lifshitz-van der Waals; $\gamma_{s}^{+}$, Lewis acid; $\gamma_{s}^{-}$, Lewis base. ${ }^{c}$ Prior to annealing ( $20 \mathrm{~nm}$ thick).

After annealing to remove physisorbed molecules, all $\mathrm{AlO}_{x} /$ $\mathrm{C}_{n} \mathrm{PA}$ surfaces have low surface energy of $\sim 17.5 \mathrm{~mJ} / \mathrm{m}^{2}$ with dominating Lifshitz-van der Waals (dispersive) component. No correlation between surface properties and length of the aliphatic chain is observed. The small Lewis acid component and negligible Lewis base component indicate that the surface has some electron-pair-accepting ability. On the contrary, surface energy of the $\sim 20 \mathrm{~nm}$ thick $\mathrm{C}_{18} \mathrm{PA}$ layer prior to annealing is much higher at $\sim 31 \mathrm{~mJ} / \mathrm{m}^{2}$. The larger surface energy suggests that some $\mathrm{C}_{n} \mathrm{PA}$ head groups are found on the surface. In this case the Lewis base component dominates (the surface has electron-pair-donating ability), followed by the sizable Lifshitz-van der Waals energy, which is about $50 \%$ higher than that of $\mathrm{C}_{n} \mathrm{PA}$ monolayers after annealing. While $\mathrm{C}_{n} \mathrm{PA}$ molecules are likely to be "standing up" in the monolayers as a result of their bonding to $\mathrm{AlO}_{x}, \mathrm{C}_{18} \mathrm{PA}$ molecules that form the top surface of a $20 \mathrm{~nm}$ thick layer are expected to assume random orientations, resulting in exposed - $\mathrm{OH}$ groups and different surface properties.

Comparing these results to those obtained for solutionassembled $\mathrm{C}_{n} \mathrm{PA}$, one would notice that solution-assembled monolayers exhibit slightly lower contact angles for FW and DIM and higher surface energies ranging between 25 and 30 $\mathrm{mJ} / \mathrm{m}^{2}{ }^{34}$ However, this difference may result from the fact that ref 34 reports results for alkylphosphonic acids on sol-gelderived hafnium oxide, while our results are for $\mathrm{C}_{n} \mathrm{PA}$ on aluminum oxide.

$\mathrm{AlO}_{x} / \mathrm{C}_{n} \mathrm{PA}$ surfaces were also investigated by AFM (see Table 2). In addition to determining the root-mean-square (RMS) surface roughness, the use of a new PeakForce QNM scanning mode enabled direct extraction of quantitative nanomechanical information such as force of adhesion $\left(F_{\mathrm{ad}}\right)$, elastic modulus $(E)$, deformation, and dissipation. The surface roughness $\left(R_{\mathrm{a}}\right)$ of $\sim 10 \mathrm{~nm}$ thick $\mathrm{AlO}_{x}$ is $1.27 \mathrm{~nm}$. The 3-h anneal at $160{ }^{\circ} \mathrm{C}$ does not affect its surface roughness, confirming that $\mathrm{C}_{n} \mathrm{PA}$ desorption/annealing step would not lead to increased surface roughness of the $\mathrm{AlO}_{x} / \mathrm{C}_{n} \mathrm{PA}$ dielectric due to increased roughness of $\mathrm{AlO}_{x}$. The surface roughness of $\mathrm{AlO}_{x}$ functionalized with $\mathrm{C}_{n} \mathrm{PA}$ is comparable or slightly higher but below $2 \mathrm{~nm}$ in most cases. The $\mathrm{C}_{18} \mathrm{PA}$ layer prior to annealing has a roughness of $2.25 \mathrm{~nm}$. There is no correlation between $\mathrm{AlO}_{x} / \mathrm{C}_{n} \mathrm{PA}$ surface roughness and length of the phosphonic acid. In addition, no correlation is observed between $\mathrm{C}_{n} \mathrm{PA}$ length and nanomechanical properties. Force values lie between $\sim 3$ and $\sim 5 \mathrm{nN}$, moduli are between 22 and $63 \mathrm{GPa}$, deformation falls between $\sim 3$ and $\sim 8 \mathrm{~nm}$, and dissipation is between $\sim 200$ and $1000 \mathrm{eV}$. Previously, the surface roughness of alkylphosphonic acids, solution-assembled on top of $\mathrm{Si} / \mathrm{AlO}_{x}$, was affected by the length of the molecule, and the lowest surface roughness was achieved for $\mathrm{C}_{14} \mathrm{PA}{ }^{14}$

In summary, $\mathrm{AlO}_{x} / \mathrm{C}_{n} \mathrm{PA}$ surfaces after annealing exhibit comparable RMS surface roughness. While their mechanical properties on the nanometer scale (AFM tip size is $2 \mathrm{~nm}$ ) vary by a factor of $2-5$ (see Table 2), their macroscopic surface properties (see Table 1) are similar.

Fourier transform infrared (FTIR) spectroscopy provides structural information on a macroscopic scale, that is, the scale of the transistor channel. FTIR was performed on $\mathrm{AlO}_{x} / \mathrm{C}_{n} \mathrm{PA}$ surfaces after annealing and on the reference $\mathrm{AlO}_{x}$ surface (see Figure 2). A strong broad absorbance near $900 \mathrm{~cm}^{-1}$ is dominated by $\mathrm{Al}-\mathrm{O}$ vibrations in all samples. Weaker vibrations are observed in the region from 1000 to 1250 $\mathrm{cm}^{-1}$, near $1450 \mathrm{~cm}^{-1}$, and between 2800 and $3000 \mathrm{~cm}^{-1}$. In general, the integral intensity of various peaks is higher for shorter-chain $\mathrm{C}_{n} \mathrm{PA}$ and lower for longer chains. As the length of the phosphonic acid is increased, the position of $\mathrm{C}-\mathrm{H}_{2}$ stretching is shifted to lower wavenumbers and their full width at half maximum (fwhm) is reduced. For $\mathrm{C}_{8} \mathrm{PA}$ the peaks are centered at $2853 \mathrm{~cm}^{-1}\left(\mathrm{fwhm}=20.7 \mathrm{~cm}^{-1}\right)$ and $2924 \mathrm{~cm}^{-1}$

Table 2. Surface Roughness and Nanomechanical Properties Determined by AFM

\begin{tabular}{|c|c|c|c|c|c|}
\hline surface & surface roughness $(\mathrm{nm})$ & force $(\mathrm{nN})$ & modulus $(\mathrm{GPa})$ & deformation $(\mathrm{nm})$ & dissipation $(\mathrm{eV})$ \\
\hline $\mathrm{C}_{8} \mathrm{PA}$ & 1.25 & $3.1 \pm 0.7$ & $63 \pm 9$ & $2.8 \pm 0.6$ & 353 \\
\hline $\mathrm{C}_{10} \mathrm{PA}$ & 1.53 & $3.6 \pm 1.1$ & $30 \pm 9$ & $3.2 \pm 0.5$ & 226 \\
\hline $\mathrm{C}_{12} \mathrm{PA}$ & 2.34 & $5.3 \pm 1.6$ & $28 \pm 10$ & $3.6 \pm 0.7$ & 1016 \\
\hline $\mathrm{C}_{14} \mathrm{PA}$ & 1.13 & $5.4 \pm 1.5$ & $29 \pm 8$ & $8.6 \pm 2.5$ & 277 \\
\hline $\mathrm{C}_{16} \mathrm{PA}$ & 1.82 & $2.8 \pm 0.6$ & $22 \pm 5$ & $4.0 \pm 0.6$ & 219 \\
\hline $\mathrm{C}_{18} \mathrm{PA}$ & 1.47 & $3.9 \pm 1.0$ & $37 \pm 11$ & $3.1 \pm 0.1$ & 945 \\
\hline $\mathrm{C}_{18} \mathrm{PA}^{a}$ & 2.25 & $3.3 \pm 1.2$ & $65 \pm 31$ & $4.2 \pm 1.1$ & 566 \\
\hline $\mathrm{AlO}_{x}$ & 1.27 & $4.9 \pm 1.3$ & $43 \pm 10$ & $4.4 \pm 0.1$ & 961 \\
\hline $\mathrm{AlO}_{x}^{b}$ & 1.22 & $4.9 \pm 1.1$ & $65 \pm 50$ & $4.5 \pm 0.1$ & 509 \\
\hline
\end{tabular}

${ }^{a}$ Prior to annealing ( 20 nm thick). ${ }^{b}$ Annealed. 

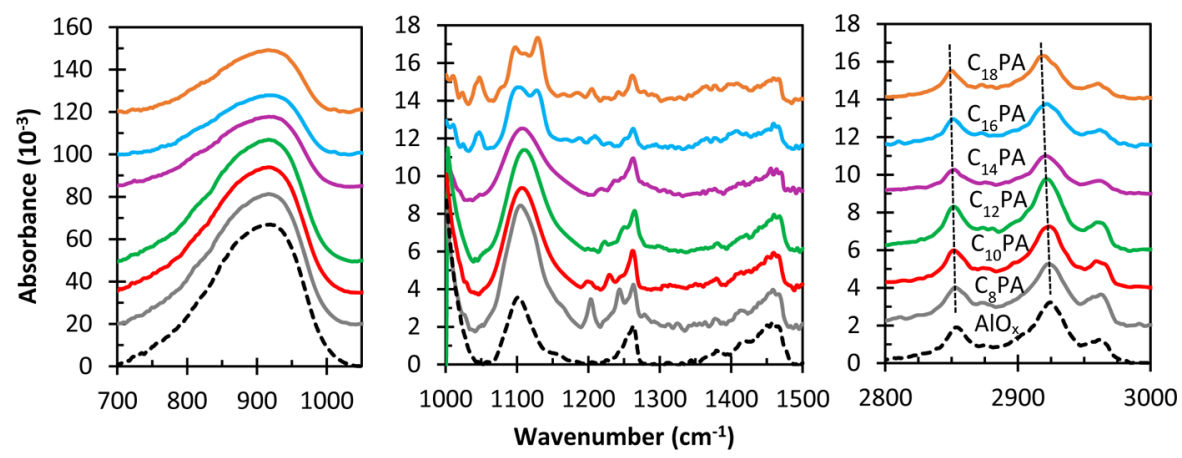

Figure 2. FTIR spectra of $\mathrm{AlO}_{x} / \mathrm{C}_{n} \mathrm{PA}$ bilayers. Bare annealed $\mathrm{AlO}_{x}$ is included for comparison. Individual spectra are offset by a constant value to allow easier viewing.

$\left(\mathrm{fwhm}=31.9 \mathrm{~cm}^{-1}\right)$, while for $\mathrm{C}_{18} \mathrm{PA}$ the peaks are found at $2850 \mathrm{~cm}^{-1}\left(\right.$ fwhm $\left.=17.3 \mathrm{~cm}^{-1}\right)$ and $2920 \mathrm{~cm}^{-1}(\mathrm{fwhm}=28.4$ $\left.\mathrm{cm}^{-1}\right)$. These peak positions are very similar to those reported for $\mathrm{C}_{n} \mathrm{PA}$ monolayers prepared in ethanol on hafnium oxide. ${ }^{34}$ The shift in the peak location was previously interpreted as an improved molecular order within monolayers; that is, the increase in $\mathrm{C}_{n} \mathrm{PA}$ length leads to stronger van der Waals interaction between aliphatic chains and results in a more ordered self-assembly with denser molecular packing. ${ }^{35-37}$ However, one would predict that the density of vacuumdeposited monolayers would be lower than that of solutiondeposited monolayers as a result of the laws that govern physical vapor deposition. This is supported by the fact that the integral intensity of $\mathrm{CH}_{2}$ stretches near 2850 and $2920 \mathrm{~cm}^{-1}$ does not increase with increasing length of $\mathrm{C}_{n} \mathrm{PA}$. As seen in Figure 2, the integral intensity of these spectral lines is comparable for $\mathrm{C}_{8}, \mathrm{C}_{10}$, and $\mathrm{C}_{12} \mathrm{PA}$ and lower for $\mathrm{C}_{14}, \mathrm{C}_{16}$, and $\mathrm{C}_{18} \mathrm{PA}$ monolayers, suggesting lower molecular coverage for longer $\mathrm{C}_{n} \mathrm{PAs}$.

In summary, $\mathrm{CH}_{2}$ stretching vibrations confirm that a degree of order exists even for vacuum-deposited monolayers, and the molecular order improves with increasing length of $\mathrm{C}_{n} \mathrm{PA}$. The spread in nanomechanical properties suggests heterogeneous monolayer structure, such as presence of domains or nanopores. Previously, molecular dynamic simulations performed on solution-assembled $\mathrm{C}_{n} \mathrm{PA}$ monolayers on aluminum oxide confirmed a change in the morphology from amorphous to quasi-crystalline with increasing length of $\mathrm{C}_{n} \mathrm{PA}{ }^{19}$ In such a case, highly ordered domains with gaps between them exist for long $\mathrm{C}_{n} \mathrm{PA}$ molecules.

3.2. Organic Field-Effect Transistors: As Fabricated and Under Bias Stress. The cross-section of the bottom gate $\mathrm{Al} / \mathrm{AlO}_{x} / \mathrm{C}_{n} \mathrm{PA} / \mathrm{DNTT} / \mathrm{Au}$ transistor is shown is Figure $3 \mathrm{a}$. Figure $3 \mathrm{~b}$ shows transistor transfer characteristics for asfabricated transistors with various phosphonic acid monolayers. As $\mathrm{C}_{n} \mathrm{PA}$ length increases, threshold voltage $\left(V_{\mathrm{T}}\right)$ and transistor off-current $\left(I_{\text {off }}\right)$ decrease. Figure $3 \mathrm{c}$ depicts output characteristics of an OFET with $\mathrm{C}_{18} \mathrm{PA}$ and nominal channel length of $30 \mu \mathrm{m}$. The behavior of all transistor parameters for asfabricated transistors is shown in Figure $3 \mathrm{~d}-\mathrm{i}$. Upon going from $\mathrm{C}_{8} \mathrm{PA}$ to $\mathrm{C}_{18} \mathrm{PA}$, mean threshold voltage $\left(V_{\mathrm{T}}\right)$ decreases from -1.37 to $-1.24 \mathrm{~V}$, field-effect mobility $(\mu)$ increases from 0.03 to $0.33 \mathrm{~cm}^{2} /(\mathrm{V} \cdot \mathrm{s})$, subthreshold slope $(S)$ remains the same within the error of measurement (variation between 86 and 94 $\mathrm{mV} /$ decade), off-current $\left(I_{\text {off }}\right)$ decreases from $\sim 8 \times 10^{-13}$ to $\sim 3$ $\times 10^{-13} \mathrm{~A}$, and for OFETs with $L=30 \mu \mathrm{m}$, on-current $\left(I_{\text {on }}\right)$ increases from $\sim 3 \times 10^{-8}$ to $\sim 2 \times 10^{-6} \mathrm{~A}$ and on/off-current ratio $\left(I_{\text {on }} / I_{\text {off }}\right)$ increases from $\sim 3 \times 10^{4}$ to $\sim 4 \times 10^{6}$.
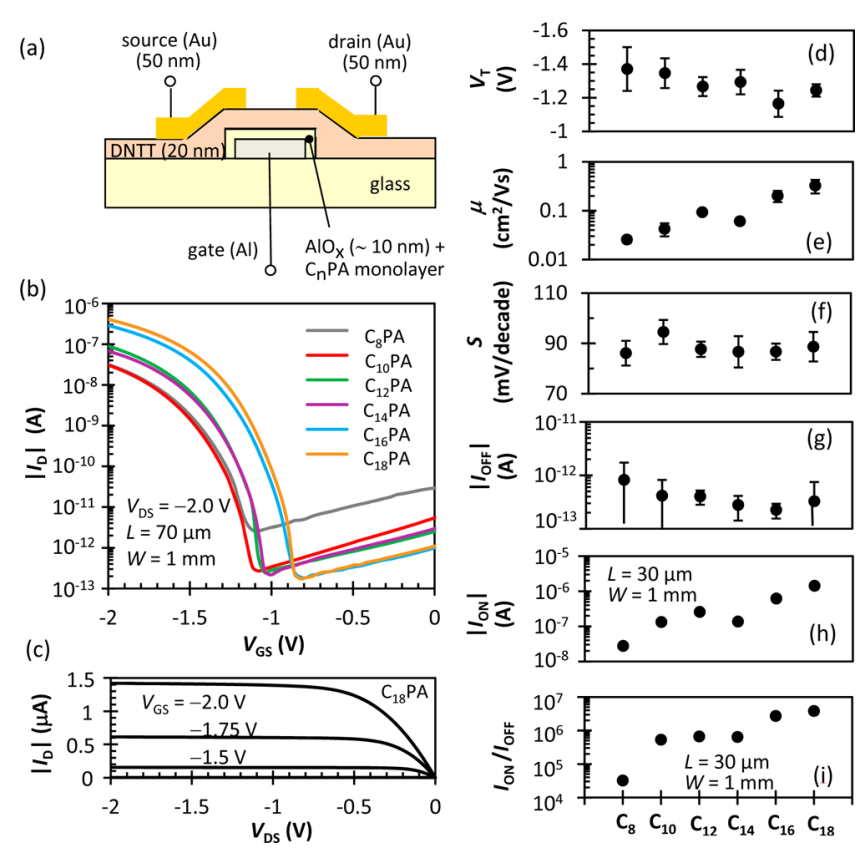

Figure 3. (a) OFET cross-section. (b) Transistor transfer characteristics as a function of $\mathrm{C}_{n} \mathrm{PA}$. (c) Transistor output characteristics for $\mathrm{C}_{18}$ PA. $(\mathrm{d}-\mathrm{i})$ Parameters of as-fabricated transistors as functions of $\mathrm{C}_{n} \mathrm{PA}$.

Overall, increasing length of the phosphonic acid leads to a significant improvement of transistor parameters. This behavior is different from the behavior of transistors that incorporated solution-assembled $\mathrm{C}_{n} \mathrm{PAs}$. For $\mathrm{Si} / \mathrm{HfO}_{2} / \mathrm{C}_{n} \mathrm{PA} /$ pentacene/Au OFETs, threshold voltage became more negative with increasing $\mathrm{C}_{n} \mathrm{PA}$ length, while mobility of $\mathrm{C}_{8}-\mathrm{C}_{14} \mathrm{PA}$ exceeded that of $\mathrm{C}_{16}-\mathrm{C}_{18} \mathrm{PA}^{34}$ For $\mathrm{Si} / \mathrm{AlO}_{x} / \mathrm{C}_{n} \mathrm{PA} /$ pentacene/Au OFETs, threshold voltage did not change significantly and mobility peaked for $\mathrm{C}_{14} \mathrm{PA} .{ }^{14}$ For $\mathrm{Si} / \mathrm{SiO}_{2} / \mathrm{C}_{n} \mathrm{PA} /$ pentacene/Au OFETs, the lowest threshold voltage occurred for $\mathrm{C}_{8} \mathrm{PA}$, mobility decreased from $\mathrm{C}_{8} \mathrm{PA}$ to $\mathrm{C}_{18} \mathrm{PA}$, and subthreshold slope was unaffected. ${ }^{38}$ For $\mathrm{Al} / \mathrm{AlO}_{x} / \mathrm{C}_{n} \mathrm{PA} /$ pentacene/Au OFETs, mobility peaked for $\mathrm{C}_{14} \mathrm{PA}$ for oxygen-plasma $\mathrm{AlO}_{x}$ and increased with increasing $\mathrm{C}_{n} \mathrm{PA}$ length for mild-air-plasma $\mathrm{AlO}_{x \cdot}{ }^{13}$ For $\mathrm{Si} / \mathrm{AlO}_{x} / \mathrm{C}_{n} \mathrm{PA} /$ pentacene/Au OFETs, both mobility and threshold voltage increased with increasing $\mathrm{C}_{n}$ PA length. ${ }^{19}$

Comparison of our $\mathrm{C}_{18} \mathrm{PA}$ transistors to recently reported DNTT transistors that use other gate dielectrics is as follows. Cross-linked poly(ethylene-alt-maleic anhydride) (PEMA) led to a mobility of $0.11 \mathrm{~cm}^{2} /(\mathrm{V} \cdot \mathrm{s})$, while PEMA modified with 
poly (maleic anhydride-alt-1-octadecane) resulted in mobility of $0.24 \mathrm{~cm}^{2} /(\mathrm{V} \cdot \mathrm{s}) .{ }^{39}$ Octylamine-treated PEMA gate dielectric led to mobility of $0.17 \mathrm{~cm}^{2} /(\mathrm{V} \cdot \mathrm{s}) .{ }^{40}$ Vapor-jet-deposited DNTT on polystyrene-buffered poly(tripropylene glycol diacrylate) dielectric achieved a mobility of $0.43 \mathrm{~cm}^{2} /(\mathrm{V} \cdot \mathrm{s}) .{ }^{41}$ Field-effect mobilities in excess of $1 \mathrm{~cm}^{2} /(\mathrm{V} \cdot \mathrm{s})$ were achieved when gate dielectrics incorporating organic monolayers were used. ${ }^{42-44}$ Threshold voltage and subthreshold slope depend on the thickness of the gate dielectric, and our values are consistent with the values achieved for other thin dielectrics. Similarly, comparison of the on/off ratio is difficult because it depends on transistor dimensions.

A short bias stress lasting for $1000 \mathrm{~s}$ was also performed. During the bias stress, a voltage of $-2 \mathrm{~V}$ was applied to the gate while source and drain electrodes were grounded. All samples were kept in dark ambient air for 3 days before the bias stress was performed. Figure $4 \mathrm{a}$ shows the evolution of threshold
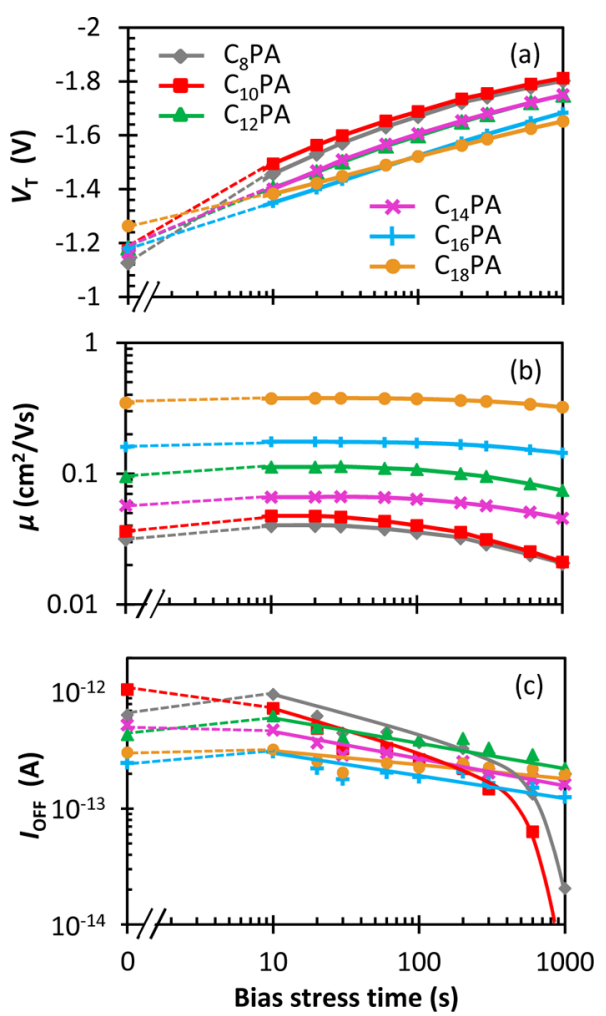

Figure 4. (a) Threshold voltage, (b) field-effect mobility, and (c) offcurrent as functions of bias stress time for transistors with various $\mathrm{C}_{n} \mathrm{PA}$.

voltage with increasing bias stress time. While transistors incorporating $\mathrm{C}_{16} \mathrm{PA}$ and $\mathrm{C}_{18} \mathrm{PA}$ monolayers exhibit initial threshold voltage similar to that shown in Figure 3, transistors with shorter phosphonic acids exhibit lower initial $\left|V_{\mathrm{T}}\right|$, indicating poorer ambient stability. Initial values of mobility and off-current are similar to those shown in Figure 3.

Bias stress leads to a more negative threshold voltage for all transistors; however, the rate of degradation decreases as length of the phosphonic acid increases, making transistors with $\mathrm{C}_{18} \mathrm{PA}$ almost a factor of 2 more stable than those with $\mathrm{C}_{8} \mathrm{PA}$. Degradation in field-effect mobility (see Figure $4 \mathrm{~b}$ ) exhibits different behavior for various $\mathrm{C}_{n} \mathrm{PA}$. For $\mathrm{C}_{18} \mathrm{PA}$ and $\mathrm{C}_{16} \mathrm{PA}$, mobility exhibits only a minor change, reaching $\sim 93 \%$ of the initial value at $1000 \mathrm{~s}$. For $\mathrm{C}_{14} \mathrm{PA}$ and $\mathrm{C}_{12} \mathrm{PA}$, mobility first increases by about $20 \%$ and then decreases to about $80 \%$ of the initial value. For the shortest $\mathrm{C}_{n} \mathrm{PA}$, mobility first increases by $30-35 \%$ and then decreases to about $60 \%$ of the initial value. Off-current decreases for all $\mathrm{C}_{n} \mathrm{PA}$ (see Figure 4c). While the decrease is almost negligible for longer $\mathrm{C}_{n} \mathrm{PA}$, the drop in $I_{\text {off }}$ is much more pronounced for $\mathrm{C}_{8} \mathrm{PA}$ and $\mathrm{C}_{10} \mathrm{PA}$.

It has been shown that bias-stress degradation of DNTT transistors with polystyrene-buffered poly(tripropylene glycol diacrylate) dielectric depends on environmental conditions. ${ }^{25}$ Since all our transistors were bias-stressed in the same laboratory environment (air, $\sim 40 \%$ relative humidity), differences in their degradation are ascribed to transistor structure.

The choice of $\mathrm{C}_{n} \mathrm{PA}$ affects gate dielectric capacitance (see Figure 1) and threshold voltage of the transistors (see Figure 3). Therefore, one should consider the induced capacitive charge at the beginning of the transistor bias-stress degradation. Since the gate-to-channel voltage is not known, the gate-tosource voltage $V_{\mathrm{GS}}$ is used to approximate the accumulated charge; that is, $Q=C\left|V_{\mathrm{GS}}-V_{\mathrm{T}}\right|$. This charge is $0.41 \mu \mathrm{C} / \mathrm{cm}^{2}$ for $\mathrm{C}_{8} \mathrm{PA}, 0.24 \mu \mathrm{C} / \mathrm{cm}^{2}$ for $\mathrm{C}_{18} \mathrm{PA}$, and $0.31-0.33 \mu \mathrm{C} / \mathrm{cm}^{2}$ for the remaining $\mathrm{C}_{n} \mathrm{PA}$. If transistor bias degradation were solely controlled by induced charge density, then transistors with $\mathrm{C}_{10}$, $\mathrm{C}_{12}, \mathrm{C}_{14}$, and $\mathrm{C}_{16} \mathrm{PA}$ should exhibit similar degradation behavior. However, the results of Figure 4 show degradation that is clearly linked to length of the phosphonic acid instead of induced charge density.

The experimental results confirm strong correlation between initial and bias-induced transistor behavior and length of the $\mathrm{C}_{n} \mathrm{PA}$ monolayer. Overall, the transistors exhibit improved initial parameters and ambient and bias-stress stability when $\mathrm{C}_{n} \mathrm{PA}$ length increases. FTIR vibrations between 2800 and 3000 $\mathrm{cm}^{-1}$ indicate a degree of order within the monolayer that improves with increasing $\mathrm{C}_{n} \mathrm{PA}$ length. Our discussion will now focus on DFT results and parts of the FTIR spectra that "probe" the bonding of $\mathrm{C}_{n} \mathrm{PA}$ to $\mathrm{AlO}_{x}$.

3.3. Density Functional Theory. As shown above, water contact angles and surface energy are the same for all $\mathrm{AlO}_{x} /$ $\mathrm{C}_{n} \mathrm{PA}$ surfaces after annealing. Minor differences in RMS surface roughness are not correlated to the length of $\mathrm{C}_{n} \mathrm{PA}$. However, FTIR spectra show differences and so does the transistor behavior. DFT was therefore used to calculate vibration frequencies of different $\mathrm{C}_{n} \mathrm{PA}$ molecules in their free state as well as bonded to stoichiometric $\mathrm{Al}_{2} \mathrm{O}_{3}$. Here, monodentate and bidentate bonding was considered.

Figure 5 shows sections of the vibration spectra calculated from DFT. Vibrations exist below $700 \mathrm{~cm}^{-1}$; however, this section is not shown as there are no experimental data to match it. For free acids, $\mathrm{P}-\mathrm{OH}$ vibrations are located between $\sim 800$ and $\sim 850 \mathrm{~cm}^{-1}, \mathrm{P}=\mathrm{O}$ is found near $1250 \mathrm{~cm}^{-1}$, and $\mathrm{CH}_{3} / \mathrm{CH}_{2}$ stretches occur between 2930 and $\sim 3050 \mathrm{~cm}^{-1}$. These frequencies can be compared with calculations from selfconsistent charge density-functional tight binding (SCCDFTB $),{ }^{45}$ which is based on DFT but is a more approximate method. Such calculations gave $\mathrm{P}-\mathrm{OH}$ vibrations in the range $625-683 \mathrm{~cm}^{-1}, \mathrm{P}=\mathrm{O}$ vibration of $1324 \mathrm{~cm}^{-1}$, and $\mathrm{CH}_{2} / \mathrm{CH}_{3}$ vibrations in the region between 2750 and $3000 \mathrm{~cm}^{-1}$. For monodentate attachment of $\mathrm{C}_{n} \mathrm{PA}$ (see Figure 5), the region between 700 and $1000 \mathrm{~cm}^{-1}$ contains $\mathrm{AlO}, \mathrm{P}-\mathrm{OAl}, \mathrm{P}-\mathrm{OH}$, and $\mathrm{P}-\mathrm{C}$ vibrations. $\mathrm{AlO}-\mathrm{H}$ bending and $\mathrm{P}=\mathrm{O}$ stretching are both found near 1025 and $1150 \mathrm{~cm}^{-1}$; however, AlO-H bending contributes more strongly to the vibration at 1025 $\mathrm{cm}^{-1}$, while $\mathrm{P}=\mathrm{O}$ stretch dominates the vibration near 1150 $\mathrm{cm}^{-1}$. $\mathrm{C}_{n} \mathrm{PA}$ length does not affect the position of these peaks. 

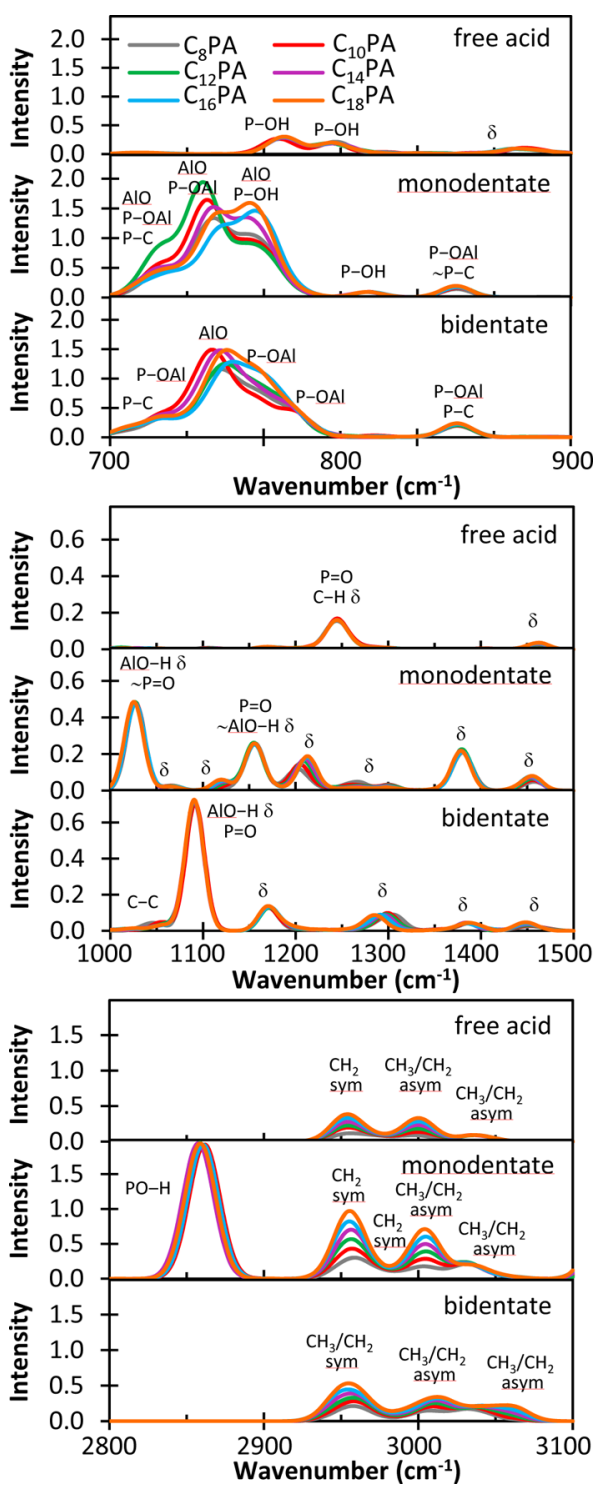

Figure 5. DFT vibration spectra for various $\mathrm{C}_{n} \mathrm{PAs}$, as free acids and for monodentate and bidentate attachments to stoichiometric $\mathrm{Al}_{2} \mathrm{O}_{3} . \delta$ signifies a bending mode.

The two main $\mathrm{CH}_{3} / \mathrm{CH}_{2}$ stretches are pushed further apart due to $\mathrm{CH}_{3} / \mathrm{CH}_{2}$ asymmetric stretching being shifted to slightly higher wavenumbers. The $\mathrm{P}=\mathrm{O}$ frequency of $1150 \mathrm{~cm}^{-1}$ can be compared to the SCC-DFTB value of $1320 \mathrm{~cm}^{-1}$ for phosphonic acid $\mathrm{HPO}(\mathrm{OH})_{2}$ on alumina ${ }^{45}$ and to an experimental value of $1278 \mathrm{~cm}^{-1}$ for $\mathrm{C}_{18} \mathrm{PA}$ acid on silicon. ${ }^{46}$ DFT calculations of alkylphosphonic acids on silicon gave $\mathrm{CH}_{3} / \mathrm{CH}_{2}$ frequencies in the range $2925-3075 \mathrm{~cm}^{-1}$. ${ }^{46}$ Finally, for bidentate attachment of $\mathrm{C}_{n} \mathrm{PA}$ (see Figure 5), the region between 700 and $1000 \mathrm{~cm}^{-1}$ contains $\mathrm{AlO}, \mathrm{P}-\mathrm{OAl}$, and $\mathrm{P}-\mathrm{C}$ vibrations. $\mathrm{AlO}-\mathrm{H}$ bending and $\mathrm{P}=\mathrm{O}$ stretch are both found near $1100 \mathrm{~cm}^{-1}$, and $\mathrm{C}_{n} \mathrm{PA}$ length does not affect the position or intensity of this peak. The two main $\mathrm{CH}_{3} / \mathrm{CH}_{2}$ stretches are pushed even further apart due to an additional shift of $\mathrm{CH}_{3}$ / $\mathrm{CH}_{2}$ asymmetric stretching to higher wavenumbers. The second $\mathrm{CH}_{3} / \mathrm{CH}_{2}$ asymmetric stretch is also shifted to higher wavenumbers. For $\mathrm{HPO}(\mathrm{OH})_{2}$ on alumina, SCC-DFTB gave the $\mathrm{P}=\mathrm{O}$ frequency as $1325 \mathrm{~cm}^{-1}$, which is very similar to their monodentate value. ${ }^{45}$
Compared to the measured data of Figure 2, calculated positions of $\mathrm{CH}_{3} / \mathrm{CH}_{2}$ stretches are shifted to higher wavenumbers for all bonded phosphonic acids. This could be for two reasons: (a) DFT approximation of exchange and correlation effects and (b) neglect of dynamic (finite temperature) effects. Inclusion of van der Waals interactions that partially account for electron correlation effects may improve the DFT results, as has been shown for the case of water. ${ }^{47}$

Overall, the most significant differences in vibration spectra between monodentate and bidentate attachments are in the regions $750-800 \mathrm{~cm}^{-1}$ and $1000-1200 \mathrm{~cm}^{-1}$. While the former is buried in the strong AlO peak of measured FTIR spectra, the second region can be used to analyze the experimental data. DFT also showed that the tilt of $\mathrm{C}_{n} \mathrm{PA}$ with respect to the surface normal decreases with increasing length of the molecule, and for any $\mathrm{C}_{n} \mathrm{PA}$ the bidentate attachment results in a smaller tilt when compared to the monodentate attachment (see Supporting Information). Tilt angles are smaller than those predicted by the SCC-DFTB method, ${ }^{48}$ but this is to be expected as our coverage is higher, forcing the molecules to be more upright.

Previous research has shown that phosphonic acids selfassembled from solutions strongly attach to aluminum oxide. ${ }^{49}$ Attachment is facilitated by the headgroup that reacts with surface hydroxyl groups of aluminum oxide. ${ }^{50}$ When the metal oxide surface possesses Lewis acidic sites, binding originates from coordination of $\mathrm{P}=\mathrm{O}$ to such a site, followed by the condensation reaction between $\mathrm{P}-\mathrm{OH}$ and $\mathrm{Al}-\mathrm{OH}$ moieties to produce $\mathrm{P}-\mathrm{O}-\mathrm{Al}$ bonds. ${ }^{51}$ This ultimately leads to tridentate $\mathrm{C}_{n} \mathrm{PA}$ attachment. On metal oxides lacking Lewis acidity, reaction between $\mathrm{P}-\mathrm{OH}$ and $\mathrm{Al}-\mathrm{OH}$ moieties results in bidentate attachment. ${ }^{51}$ Tridentate attachment is also possible when a hydrogen bond between surface $-\mathrm{OH}$ and $\mathrm{P}=\mathrm{O}$ moieties is formed. Another proposed mechanism involves protonation of surface $-\mathrm{OH}$ groups followed by formation of the $\mathrm{P}-\mathrm{O}-\mathrm{Al}$ bond. ${ }^{48,52}$ In such a case, the phosphorus atom is left with a positive charge. In addition, DFT calculations have shown that the thermodynamically preferred binding mode depends on surface structure of the aluminum oxide and the amount of residual water. ${ }^{53}$

DFT calculations show that monodentate binding of $\mathrm{C}_{n} \mathrm{PA}$ to $\mathrm{Al}_{2} \mathrm{O}_{3}$ results in a strong $\mathrm{PO}-\mathrm{H}$ vibration found below the region of $\mathrm{CH}_{2} / \mathrm{CH}_{3}$ stretches. Since measured FTIR spectra of all $\mathrm{C}_{n} \mathrm{PA}$ monolayers lack such vibrations, monodentate attachment is unlikely for vacuum-deposited monolayers. This is further supported by the presence of a broad vibration band near $1100 \mathrm{~cm}^{-1}$, consistent with bidentate bonding. DFT assigns this vibration band to $\mathrm{AlO}-\mathrm{H}$ bending and $\mathrm{P}=\mathrm{O}$ stretching. The measured integral intensity of this band decreases with increasing $\mathrm{C}_{n} \mathrm{PA}$ length, and the contributing vibration frequencies move slightly apart. This is interpreted as reduced $\mathrm{C}_{n} \mathrm{PA}$ coverage because similar reduction in the integral intensity of $\mathrm{CH}_{2}$ stretches is observed for longer $\mathrm{C}_{n} \mathrm{PA}$. This also agrees with the expected random orientation of $\mathrm{C}_{n} \mathrm{PA}$ molecules during physical vapor deposition and the area each molecule is likely to occupy. Another possibility is that some $\mathrm{P}=\mathrm{O}$ bonds disappear as a result of tridentate attachment. However, if tridentate attachment occurred for longer $\mathrm{C}_{n} \mathrm{PA}$ via protonation of surface $-\mathrm{OH}$ groups, the resulting immobile positive charge should lead to a more negative threshold voltage, which is not observed. Formation of a hydrogen bond between surface $-\mathrm{OH}$ and $\mathrm{P}=\mathrm{O}$ moieties is more plausible, because it would lead to a shift in $\mathrm{AlO}-\mathrm{H}$ and $\mathrm{P}=\mathrm{O}$ vibration 
frequencies and no immobile charge. Consequently, tridentate attachment via hydrogen bond cannot be excluded.

3.4. Final Remarks. We would like to make a few remarks about the observed transistor behavior. Negatively charged immobile species in the presence of hydroxyl groups were demonstrated in the case of $\mathrm{Si}-\mathrm{OH}$ when silicon dioxide was used as gate dielectric ${ }^{54}$ or as a result of electrochemical reactions that involve adsorbed water. ${ }^{55}$ The presence of $\mathrm{Al}-$ $\mathrm{OH}$ groups on the surface of $\mathrm{AlO}_{x}$ could also lead to fixed negative charge located at the $\mathrm{AlO}_{x} / \mathrm{C}_{n} \mathrm{PA}$ interface. Since more $\mathrm{Al}-\mathrm{OH}$ sites would be expected for longer $\mathrm{C}_{n} \mathrm{PA}$ when fewer molecules are attached to $\mathrm{AlO}_{x}$, lower threshold voltage is expected for longer $\mathrm{C}_{n} \mathrm{PA}$. This is indeed observed for asfabricated transistors. However, the presence of $\mathrm{Al}-\mathrm{OH}$ sites does not explain the different ambient and bias-stress degradations.

Phosphonic acids possess a dipole moment that has been shown to control the threshold voltage of the transistors. ${ }^{56}$ The component normal to the $\mathrm{AlO}_{x}$ surface is quite small if the molecule stands perpendicular to the surface. ${ }^{56}$ This component would change with length and tilt of the $\mathrm{C}_{n} \mathrm{PA}$ molecule. Bending of the longer molecules observed by DFT would complicate matters even more. The existence of dipole moments can potentially explain the observed differences in $\left|V_{\mathrm{T}}\right|$ for as-fabricated transistors. However, it cannot explain the different ambient and bias-stress degradations.

Another possibility involves the reduced density of $\mathrm{C}_{n} \mathrm{PA}$ monolayers for longer molecules. Lower molecular coverage can be intentionally induced by substrate heating during $\mathrm{C}_{n} \mathrm{PA}$ growth. ${ }^{22}$ Our previous experiments with $\mathrm{C}_{8} \mathrm{PA}$ and pentacene showed an increase in $\left|V_{\mathrm{T}}\right|$ and a decrease in field-effect mobility with increasing $\mathrm{C}_{8} \mathrm{PA}$ growth temperature. ${ }^{22}$ This behavior is opposite to that observed in Figure 3, and therefore, varied molecular density is an unlikely cause of the change in threshold voltage.

Finally, changing morphology of the monolayers with increasing $\mathrm{C}_{n} \mathrm{PA}$ length could have a profound effect on the growth of DNTT. The large increase in field-effect mobility and the dissimilar degradation behavior must be controlled by the $\mathrm{C}_{n} \mathrm{PA} / \mathrm{DNTT}$ interface and/or DNTT itself. Additional research is needed to understand how these vacuum-evaporated alkylphosphonic acids control the growth of DNTT.

\section{CONCLUSION}

Growth that self-limits the thickness of materials is desirable for ultrathin dielectrics for low-voltage transistors. In this paper, we showed that monolayers of alkylphosphonic acids $\left(C_{8}-C_{18}\right)$ can be prepared by vacuum evaporation and incorporated into organic field-effect transistors based on DNTT.

$\mathrm{AlO}_{x} / \mathrm{C}_{n} \mathrm{PA}$ bilayers $(\sim 11-12 \mathrm{~nm}$ thick) exhibit low leakage current densities ranging between $\sim 6 \times 10^{-8}$ and $\sim 3 \times 10^{-8} \mathrm{~A} /$ $\mathrm{cm}^{2}$ at $-3 \mathrm{~V}$. The decrease in capacitance with increasing length of $\mathrm{C}_{n} \mathrm{PA}$ confirms monolayer formation for all phosphonic acids. Total surface energy of $\mathrm{AlO}_{x} / \mathrm{C}_{n} \mathrm{PA}$ surfaces after annealing is $\sim 17.5 \mathrm{~mJ} / \mathrm{m}^{2}$ and independent of $\mathrm{C}_{n} \mathrm{PA}$ length. All $\mathrm{AlO}_{x} / \mathrm{C}_{n} \mathrm{PA}$ surfaces exhibit comparable RMS surface roughness. While their macroscopic surface properties are similar, the mechanical properties on the nanometer scale vary by a factor of 2-5. Similarly to solution-assembled monolayers, the $\mathrm{CH}_{2}$ stretching peaks narrow and shift to lower wavenumbers, confirming that molecular order improves with increasing length of $\mathrm{C}_{n} \mathrm{PA}$. At the same time, reduced molecular coverage appears for longer $\mathrm{C}_{n} \mathrm{PAs}$. The spread in nano- mechanical properties suggests a heterogeneous monolayer structure, such as the presence of domains or nanopores.

Performance of as-fabricated transistors is affected considerably by the chosen $\mathrm{C}_{n} \mathrm{PA}$. Upon going from $\mathrm{C}_{8} \mathrm{PA}$ to $\mathrm{C}_{18} \mathrm{PA}$, threshold voltage moves closer to zero by $\sim 10 \%$, field-effect mobility increases by an order of magnitude, off-current decreases by $\sim 50 \%$, and subthreshold slope does not visibly change. As a result, on-current and on/off-current ratio increase by 2 orders of magnitude for OFETs with $L=30 \mu \mathrm{m}$. Increasing $\mathrm{C}_{n} \mathrm{PA}$ length leads to a significant improvement of transistor parameters. Results of bias stress also confirm that degradation behavior is linked to length of the phosphonic acid instead of induced charge density. As $\mathrm{C}_{n} \mathrm{PA}$ length increases, transistors are less prone to bias stress. In addition, transistors with longer $\mathrm{C}_{n} \mathrm{PA}$ exhibit better air stability.

DFT calculations show that bonding of $\mathrm{C}_{n} \mathrm{PA}$ molecules (monodentate versus bidentate) results in different vibration frequencies between 1000 and $1200 \mathrm{~cm}^{-1}$. Strong PO-H vibration is also present for monodentate bonding. Comparison of DFT results and FTIR measurements leads to the conclusion that monodentate bonding does not occur for any $\mathrm{C}_{n} \mathrm{PA}$.

\section{ASSOCIATED CONTENT}

\section{S Supporting Information}

The Supporting Information is available free of charge on the ACS Publications website at DOI: 10.1021/acsami.6b08426.

Four figures showing images of relaxed phosphonic acids $\left(\mathrm{C}_{10}, \mathrm{C}_{14}\right.$, and $\left.\mathrm{C}_{18}\right)$ on alumina in monodentate and bidentate coordinations and comparison of DFT vibration spectra of phosphonic acids $\left(\mathrm{C}_{2}-\mathrm{C}_{18}\right)$ free and bonded to alumina (PDF)

\section{AUTHOR INFORMATION}

\section{Corresponding Authors}

*(H.G.) E-mail helena.gleskova@strath.ac.uk.

*(K.J.) E-mail karen.johnston@strath.ac.uk.

\section{Notes}

The authors declare no competing financial interest.

\section{ACKNOWLEDGMENTS}

S.H. is a recipient of a doctoral training grant funded by the Engineering and Physical Sciences Research Council (EPSRC), Grant EP/L505080/1. J.C. was funded by a WISE Bridging the Gap project, University of Strathclyde. DFT results were obtained by use of the EPSRC-funded ARCHIE-WeSt High Performance Computer (www.archie-west.ac.uk); EPSRC Grant EP/K000586/1. FTIR analysis was developed within CENTEM project CZ.1.05/2.1.00/03.0088, cofunded by the ERDF and follow-up sustainability stage CENTEM+ (LO1402) under the National Sustainability Programme I.

\section{REFERENCES}

(1) Fiore, V.; Battiato, P.; Abdinia, S.; Jacobs, S.; Chartier, I.; Coppard, R.; Klink, G.; Cantatore, E.; Ragonese, E.; Palmisano, G. An Integrated 13.56-MHz RFID Tag in a Printed Organic Complementary TFT Technology on Flexible Substrate. IEEE Trans. CircuitsSyst. I 2015, 62, 1668-1677.

(2) Cantatore, E.; Geuns, T. C. T.; Gelinck, G. H.; van Veenendaal, E.; Gruijthuijsen, A. F. A.; Schrijnemakers, L.; Drews, D.; de Leeuw, D. M. A 13.56-MHz RFID System Based on Organic Transponders. IEEE J. Solid-State Circuits 2007, 42, 84-92.

(3) Maiellaro, G.; Ragonese, E.; Castorina, A.; Jacob, S.; Benwadih, M.; Coppard, R.; Cantatore, E.; Palmisano, G. High-Gain Operational 
Transconductance Amplifiers in a Printed Complementary Organic TFT Technology on Flexible Foil. IEEE Trans. Circuits Syst. I 2013, 60, 3117-3125.

(4) Marien, H.; Steyaert, M. S. J.; van Veenendaal, E.; Heremans, P. Analog Building Blocks for Organic Smart Sensor Systems in Organic Thin-Film Transistor Technology on Flexible Plastic Foil. IEEE J. Solid-State Circuits 2012, 47, 1712-1720.

(5) Crone, B.; Dodabalapur, A.; Lin, Y. Y.; Filas, R. W.; Bao, Z.; LaDuca, A.; Sarpeshkar, R.; Katz, H. E.; Li, W. Large-Scale Complementary Integrated Circuits Based on Organic Transistors. Nature 2000, 403, 521-523.

(6) Gelinck, G. H.; Huitema, H. E. A.; Van Veenendaal, E.; Cantatore, E.; Schrijnemakers, L.; Van der Putten, J. B. P. H.; Geuns, T. C. T.; Beenhakkers, M.; Giesbers, J. B.; Huisman, B. H.; Meijer, E. J.; Benito, E. M.; Touwslager, F. J.; Marsman, A. W.; Van Rens, B. J. E.; De Leeuw, D. M. Flexible Active-Matrix Displays and Shift Registers Based on Solution-Processed Organic Transistors. Nat. Mater. 2004, 3, 106-110.

(7) Maiellaro, G.; Ragonese, E.; Gwoziecki, R.; Jacobs, S.; Marjanovic, N.; Chrapa, M.; Schleuniger, J.; Palmisano, G. Ambient Light Organic Sensor in a Printed Complementary Organic TFT Technology on Flexible Plastic Foil. IEEE Trans. Circuits Syst. I 2014, 61, 1036-1043.

(8) Scarpa, G.; Idzko, A.-L.; Yadav, A.; Martin, E.; Thalhammer, S. Toward Cheap Disposable Sensing Devices for Biological Assays. IEEE Trans. Nanotechnol. 2010, 9, 527-532.

(9) Noguchi, Y.; Sekitani, Y.; Someya, T. Organic-Transistor-Based Flexible Pressure Sensors Using Ink-Jet-Printed Electrodes and Gate Dielectric Layers. Appl. Phys. Lett. 2006, 89, 253507.

(10) Halik, M. Gate Dielectrics. In Organics Electronics: Materials, Manufacturing, and Applications; Klauk, H., Ed.; Wiley-VCH: Weinheim, Germany, 2006; pp 132-162; DOI: 10.1002/ 3527608753.ch6.

(11) Maliakal, G. Dielectric Materials: Selection and Design. In Organic Field-Effect Transistors; Bao, Z., Locklin, J., Eds.; CRC Press: Boca Raton, FL, 2007; pp 229-251.

(12) Klauk, H.; Zschieschang, U.; Pflaum, J.; Halik, M. UltralowPower Organic Complementary Circuits. Nature 2007, 445, 745-748.

(13) Jedaa, A.; Burkhardt, M.; Zschieschang, U.; Klauk, H.; Habich, D.; Schmid, G.; Halik, M. The Impact of Self-Assembled Monolayer Thickness in Hybrid Gate Dielectrics for Organic Thin-Film Transistors. Org. Electron. 2009, 10, 1442-1447.

(14) Fukuda, K.; Hamamoto, T.; Yokota, T.; Sekitani, T.; Zschieschang, U.; Klauk, H.; Someya, T. Effects of the Alkyl Chain Length in Phosphonic Acid Self-Assembled Monolayer Gate Dielectrics on the Performance and Stability of Low-Voltage Organic Thin-Film Transistors. Appl. Phys. Lett. 2009, 95, 203301.

(15) Acton, O.; Osaka, I.; Ting, G.; Hutchins, D.; Ma, H.; McCullough, R. D.; Jen, A. K.-Y. Phosphonic Acid Self-Assembled Monolayer and Amorphous Hafnium Oxide Hybrid Dielectric for High Performance Polymer Thin Film Transistors on Plastic Substrates. Appl. Phys. Lett. 2009, 95, 113305.

(16) Zschieschang, U.; Ante, F.; Yamamoto, T.; Takimiya, K.; Kuwabara, H.; Ikeda, M.; Sekitani, T.; Someya, T.; Kern, K.; Klauk, H. Flexible Low-Voltage Organic Transistors and Circuits Based on a High-Mobility Organic Semiconductor with Good Air Stability. Adv. Mater. 2010, 22, 982-985.

(17) Wöbkenberg, P. H.; Ball, J.; Kooistra, F. B.; Hummelen, J. C.; de Leeuw, D. M.; Bradley, D. D. C.; Anthopoulos, T. D. Low-Voltage Organic Transistors Based on Solution Processed Semiconductors and Self-Assembled Monolayer Gate Dielectrics. Appl. Phys. Lett. 2008, 93, 013303.

(18) Fukuda, K.; Yokota, T.; Kuribara, K.; Sekitani, T.; Zschieschang, U.; Klauk, H.; Someya, T. Thermal Stability of Organic Thin-Film Transistors with Self-Assembled Monolayer Dielectrics. Appl. Phys. Lett. 2010, 96, 053302.

(19) Novak, M.; Jäger, C. M.; Rumpel, A.; Kropp, H.; Peukert, W.; Clark, T.; Halik, M. The Morphology of Integrated Self-Assembled
Monolayers and Their Impact on Devices - A Computational and Experimental Approach. Org. Electron. 2010, 11, 1476-1482.

(20) Urasinska-Wojcik, B.; Cocherel, N.; Wilson, R.; Burroughes, J.; Opoku, J.; Turner, M. L.; Majewski, L. A. 1 V Organic Transistors with Mixed Self-Assembled Monolayer $/ \mathrm{Al}_{2} \mathrm{O}_{3}$ Gate Dielectrics. Org. Electron. 2015, 26, 20-24.

(21) Gupta, S.; Gleskova, H. Dry Growth of n-Octylphosphonic Acid Monolayer for Low-Voltage Organic Thin-Film Transistors. Org. Electron. 2013, 14, 354-361.

(22) Gupta, S.; Šutta, P.; Lamprou, D. A.; Gleskova, H. Effect of Substrate Temperature on Vapor-Phase Self-Assembly of n-Octylphosphonic Acid Monolayer for Low-Voltage Organic Thin-Film Transistors. Org. Electron. 2013, 14, 2468-2475.

(23) Gleskova, H.; Gupta, S.; Šutta, P. Structural Changes in VaporAssembled n-Octylphosphonic Acid Monolayer with Post-Deposition Annealing: Correlation with Bias-Induced Transistor Instability. Org. Electron. 2013, 14, 3000-3006.

(24) Milvich, J.; Zaki, T.; Aghamohammadi, M.; Rödel, R.; Kraft, U.; Klauk, H.; Burghartz, J. N. Flexible Low-Voltage Organic Phototransistors Based on Air-Stable Dinaphtho[2,3-b:2',3'- f]thieno[3,2b]thiophene (DNTT). Org. Electron. 2015, 20, 63-68.

(25) Ding, Z.; Abbas, G.; Assender, H. E.; Morrison, J. J.; Yeates, S. G.; Patchett, E. R.; Taylor, D. M. Effect of Oxygen, Moisture and Illumination on the Stability and Reliability of Dinaphtho[2,3-b:2', $3^{\prime}$ f] thieno[3,2-b]thiophene (DNTT) OTFTs during Operation and Storage. ACS Appl. Mater. Interfaces 2014, 6, 15224-15231.

(26) Adamson, W.; Gast, A. P. Physical Chemistry of Surfaces; WileyInterscience: New York, 1997.

(27) Zisman, W. A. Relation of the Equilibrium Contact Angle to Liquid and Solid Constitution. In Contact Angle, Wettability, and Adhesion; Gould, R. F., Ed.; Advances in Chemistry, Volume 43; American Chemical Society: Washington, DC, 1964; pp 1-51; DOI: 10.1021/ba-1964-0043.ch001.

(28) Janczuk, B.; Bialopiotrowicz, T.; Zdziennicka, A. Some Remarks on the Components of the Liquid Surface Free Energy. J. Colloid Interface Sci. 1999, 211, 96-103.

(29) Giannozzi, P.; Baroni, S.; Bonini, N.; Calandra, M.; Car, R.; Cavazzoni, C.; Ceresoli, D.; Chiarotti, G. L.; Cococcioni, M.; Dabo, I.; Dal Corso, A.; de Gironcoli, S.; Fabris, S.; Fratesi, G.; Gebauer, R.; Gerstmann, U.; Gougoussis, C.; Kokalj, A.; Lazzeri, M.; Martin-Samos, L.; Marzari, N.; Mauri, F.; Mazzarello, R.; Paolini, S.; Pasquarello, A.; Paulatto, L.; Sbraccia, C.; Scandolo, S.; Sclauzero, G.; Seitsonen, A. P.; Smogunov, A.; Umari, P.; Wentzcovitch, R. M. J. QUANTUM ESPRESSO: A Modular and Open-Source Software Project for Quantum Simulations of Materials. J. Phys.: Condens. Matter 2009, 21, No. 395502.

(30) Blochl, P. E. Projector Augmented-Wave Method. Phys. Rev. B: Condens. Matter Mater. Phys. 1994, 50, 17953-17979.

(31) Perdew, J. P.; Burke, K.; Ernzerhof, M. Generalized Gradient Approximation Made Simple. Phys. Rev. Lett. 1996, 77, 3865-3868.

(32) Hanwell, M.; Curtis, D. E.; Lonie, D. C.; Vandermeersch, T.; Zurek, E.; Hutchison, G. R. Avogadro: An Advanced Semantic Chemical Editor, Visualization, and Analysis Platform. J. Cheminf. 2012, 4, 17.

(33) Schaftenaar, G.; Noordik, J. H. Molden: A Pre- and PostProcessing Program for Molecular and Electronic Structures. J. Comput.-Aided Mol. Des. 2000, 14, 123-134.

(34) Acton, O.; Ting, G. G.; Shamberger, P. J.; Ohuchi, F. S.; Ma, H.; Jen, A. K.-Y. Dielectric Surface-Controlled Low-Voltage Organic Transistors via n-Alkyl Phosphonic Acid Self-Assembled Monolayers on High-k Metal Oxide. ACS Appl. Mater. Interfaces 2010, 2, 511-520.

(35) Love, J. C.; Estroff, L. A.; Kriebel, J. K.; Nuzzo, R. G.; Whitesides, G. M. Self-Assembled Monolayers of Thiolates on Metals as a Form of Nanotechnology. Chem. Rev. 2005, 105, 1103-1169.

(36) Schreiber, F. Structure and Growth of Self-Assembling Monolayers. Prog. Surf. Sci. 2000, 65, 151-256.

(37) Nuzzo, R. G.; Dubois, L. H.; Allara, D. L. Fundamental Studies of Microscopic Wetting on Organic Surfaces 0.1. Formation and 
Structural Characterization of a Self-Consistent Series of Polyfunctional Organic Monolayers. J. Am. Chem. Soc. 1990, 112, 558-569.

(38) Hill, I. G.; Weinert, C. M.; Kreplak, L.; van Zyl, B. P. Influence of Self-Assembled Monolayer Chain Length on Modified Gate Dielectric Pentacene Thin-Film Transistors. Appl. Phys. A: Mater. Sci. Process. 2009, 95, 81-87.

(39) Yoo, S.; Yi, M. H.; Kim, Y. H.; Jang, K.-S. One-Pot Surface Modification of Poly(ethylene-alt-maleic anhydride) Gate Insulators for Low-Voltage DNTT Thin-Film Transistors. Org. Electron. 2016, 33, 263-268.

(40) Choe, Y.-S.; Yi, M. H.; Kim, J.-H.; Kim, Y. H.; Jang, K.-S. Surface Grafting of Octylamine onto Poly(ethylene-alt-maleic anhydride) Gate Insulators for Low-Voltage DNTT Thin-Film Transistors. Phys. Chem. Chem. Phys. 2016, 18, 8522-8528.

(41) Ding, Z.; Abbas, G. A. W.; Assender, H. E.; Morrison, J. J.; Yeates, S. G.; Patchett, E. R.; Taylor, D. M. Vacuum Production of OTFTs by Vapor Jet Deposition of Dinaphtho [2,3-b:2',3'-f]thieno[3,2-b]thiophene (DNTT) on a Lauryl Acrylate Functionalized Dielectric Surface. Org. Electron. 2016, 31, 90-97.

(42) Zschieschang, U.; Ante, F.; Kälblein, D.; Yamamoto, T.; Takimiya, K.; Kuwabara, H.; Ikeda, M.; Sekitani, T.; Someya, T.; Blochwitz-Nimoth, J.; Klauk, H. Dinaphtho[2,3-b:2',3'-f]thieno[3,2b]thiophene (DNTT) Thin-Film Transistors With Improved Performance and Stability. Org. Electron. 2011, 12, 1370-1375.

(43) Chang, H.; Deng, Y.; Geng, Y.; Wang, T.; Yan, D. Effect of the Initial Stage of Film Growth on Device Performance of Organic Transistors Based on Dinaphtho[2,3-b:2',3'-f] thieno[3,2-b]thiophene (DNTT). Org. Electron. 2015, 22, 86-91.

(44) Zhang, Z.; Ren, X.; Peng, B.; Wang, Z.; Wang, X.; Pei, K.; Shan, B.; Miao, Q; Chan, P. K. L. Direct Patterning of Self-Assembled Monolayers by Stamp Printing Method and Applications in High Performance Organic Field-Effect Transistors and Complementary Inverters. Adv. Funct. Mater. 2015, 25, 6112-6121.

(45) Luschtinetz, R.; Seifert, G.; Jaehne, E.; Adler, H.-J. P. Infrared Spectra of Alkyl Phosphonic Acid Bound to Aluminum Surfaces. Macromol. Symp. 2007, 254, 248-253.

(46) Longo, R. C.; Cho, K.; Schmidt, W. G.; Chabal, Y. J.; Thissen, P. Monolayer Doping via Phosphonic Acid Grafting on Silicon: Microscopic Insight from Infrared Spectroscopy and Density Functional Theory Calculations. Adv. Funct. Mater. 2013, 23, 3471-3477.

(47) Zhang, C.; Wu, J.; Galli, G.; Gygi, F. Structural and Vibrational Properties of Liquid Water from van der Waals Density Functionals. J. Chem. Theory Comput. 2011, 7, 3054-3061.

(48) Luschtinetz, R.; Oliveira, A. F.; Duarte, H. A.; Seifert, G. Selfassembled Monolayers of Alkylphosphonic Acids on Aluminum Oxide Surfaces - A Theoretical Study. Z. Anorg. Allg. Chem. 2010, 636, $1506-1512$.

(49) Hoque, E.; DeRose, J. A.; Kulik, G.; Hoffmann, P.; Mathieu, H. J.; Bhushan, B. Alkylphosphonate Modified Aluminum Oxide Surfaces. J. Phys. Chem. B 2006, 110, 10855-10861.

(50) Giza, M.; Thissen, P.; Grundmeier, G. Adsorption Kinetics of Organo-Phosphonic Acids on Plasma-Modified Oxide-Covered Aluminum Surfaces. Langmuir 2008, 24, 8688-6894.

(51) Pujari, S. P.; Scheres, L.; Marcelis, A. T. M.; Zuilhof, H. Covalent Surface Modifications of Oxide Surfaces. Angew. Chem., Int. Ed. 2014, 53, 6322-6356.

(52) Luschtinetz, R.; Oliveira, A. F.; Frenzel, J.; Joswig, J.-O.; Seifert, G.; Duarte, H. A. Adsorption of Phosphonic and Ethylphosphonic Acid on Aluminum Oxide Surfaces. Surf. Sci. 2008, 602, 1347-1359.

(53) Bauer, T.; Schmaltz, T.; Lenz, T.; Halik, M.; Meyer, B.; Clark, T. Phosphonate- and Carboxylate-Based Self-Assembled Monolayers for Organic Devices: A Theoretical Study of Surface Binding on Aluminum Oxide with Experimental Support. ACS Appl. Mater. Interfaces 2013, 5, 6073-6080.

(54) Chua, L.-L.; Zaumseil, J.; Chang, J.-F.; Ou, E. C.-W.; Ho, P. K.H.; Sirringhaus, H.; Friend, R. H. General Observation of N-type Field-Effect Behavior in Organic Semiconductors. Nature 2005, 434, 194-199.
(55) Bobbert, P. A.; Sharma, A.; Mathijssen, S. G. J.; Kemerink, M.; de Leeuw, D. M. Operational Stability of Organic Field-Effect Transistors. Adv. Mater. 2012, 24, 1146-1158.

(56) Amin, A. Y.; Reuter, K.; Meyer-Friedrichsen, T.; Halik, M. Interface Engineering in High-Performance Low-Voltage Organic Thin-Film Transistors Based on 2,7-Dialkyl-[1]benzothieno[3,2-b] [1] benzothiophenes. Langmuir 2011, 27, 15340-15344. 